\title{
FORMAÇÃO DO PROFESSOR DE FÍSICA: ANÁLISE DO CURSO DE LICENCIATURA EM FÍSICA DO IFSP
}

\author{
FORMACIÓN DEL PROFESOR DE FÍSICA: ANÁLISIS DEL CURSO DE \\ LICENCIATURA EN FÍSICA DEL IFSP
}

\section{TEACHER TRAINING PHYSICS: ANALYSIS OF THE UNDERGRADUATE PHYSICS COURSE FOR FUTURE TEACHERS OF THE IFSP}

Alexandre Shigunov NETO ${ }^{1}$

André Coelho da SILVA ${ }^{2}$

RESUMO: O presente trabalho pretende realizar uma análise do curso de Licenciatura em Física do Instituto Federal de Educação, Ciência e Tecnologia de São Paulo (IFSP), campus Itapetininga. Tomando como referencial a legislação nacional e as Diretrizes Curriculares para os Cursos de Graduação em Física no Brasil, debruçamo-nos sobre a grade curricular do curso objetivando obter indícios a respeito do modelo de professor de física que o Brasil têm procurado formar.

PALAVRAS-CHAVE: Formação de professores. Professores. Física.

RESUMEN: El presente trabajo pretende realizar un análisis del curso de Licenciatura en Física del Instituto Federal de Educación, Ciencia y Tecnología de São Paulo (IFSP), campus Itapetininga. Tomando como referencial la legislación nacional y las Directrices Curriculares para los Cursos de Graduación en Física en Brasil, nos referimos a la red curricular del curso con el objetivo de obtener indicios acerca del modelo de profesor de física que Brasil ha intentado formar.

PALABRAS CLAVE: Formación de professores. Profesores. Física.

ABSTRACT: This work intends to carry out an analysis of the Undergraduate Physics Course for future teachers of the Federal Institute of Education, Science and Technology of São Paulo (IFSP), Itapetininga campus. Taking as reference the national legislation and the Curricular Guidelines for the Undergraduate Physics Courses in Brazil, we focus on the curricular structure of the course aiming to obtain indications regarding the model of physics teacher that Brazil have tried to form.

KEYWORDS: Teacher training. Teacher. Physics.

\footnotetext{
${ }^{1}$ Instituto Federal de São Paulo (IFSP), Itapetininga - SP - Brasil. Coordenador de Pesquisa, Inovação e Pósgraduação do IFSP Itapetininga. Editor das revistas RBIC e RIFP. E-mail: shigunov.ifsp.edu@ gmail.com ${ }_{2}^{2}$ Instituto Federal de São Paulo (IFSP), Itapetininga - SP - Brasil. Professor do Curso de Física do IFSP Itapetininga/SP. Membro do Grupo de Pesquisas Formação de Professores para o Ensino básico, técnico, tecnológico e superior (FoPeTec). Doutor em Educação. E-mail: andco_8@yahoo.com.br
}

RIAEE - Revista Ibero-Americana de Estudos em Educação, Araraquara, v. 13, n. 2, p. 871-884, abr./jun., 2018. E-ISSN: $1982-5587$. 


\section{Introdução}

As Diretrizes Curriculares dos cursos de graduação, ao serem elaborados no Governo do Presidente Fernando Henrique Cardoso trazem em seu bojo a ideologia neoliberal, procurando estabelecer nas Instituições de Ensino Superior (IES) características que facilitem a interação IES versus mercado de trabalho. Ou seja, servem como um manual, pois apresentam normas e procedimentos a serem seguidos por professores e IES, na tentativa de preparação do futuro profissional para atuar o mercado de trabalho. Visam preparar e formarem técnicos e não profissionais reflexivos. Portanto, nesses termos, as Diretrizes Curriculares dos cursos de graduação estariam voltadas a atingir objetivos de curto prazo, e atender exclusivamente aos interesses/necessidades do mercado de trabalho. Como as necessidades e exigências de formação profissional do mercado transformam-se rapidamente o profissional torna-se obsoleto rapidamente, virando uma engrenagem descartável e inútil. Por isso consideramos importante (re)pensar esse modelo de formação profissional exclusivamente técnica presente na grande maioria dos cursos de graduação no Brasil. (Shigunov Neto, 2015)

O Parecer CNE/CP n ${ }^{\circ}$ 9/2001 estabeleceu as Diretrizes Curriculares Nacionais para a Formação de Professores da Educação Básica, em nível superior, curso de licenciatura, de graduação plena.

$\mathrm{O}$ artigo primeiro do referido parecer estabelece que as Diretrizes Curriculares Nacionais para a Formação de Professores da Educação Básica, em nível superior, em curso de licenciatura, de graduação plena, se constituem de um conjunto de princípios, fundamentos e procedimentos a serem observados na organização institucional e curricular de cada estabelecimento de ensino e aplicam-se a todas as etapas e modalidades da educação básica.

$\mathrm{O}$ artigo terceiro estabelece que a formação de professores que atuarão nas diferentes etapas e modalidades da educação básica observará princípios norteadores desse preparo para o exercício profissional específico, que considerem:

I. a competência como concepção nuclear na orientação do curso; II. a coerência entre a formação oferecida e a prática esperada do futuro professor, tendo em vista: a) a simetria invertida, onde o preparo do professor, por ocorrer em lugar similar àquele em que vai atuar, demanda consistência entre o que faz na formação e o que dele se espera; b)a aprendizagem como processo de construção de conhecimentos, habilidades e valores em interação com a realidade e com os demais 
indivíduos, no qual são colocados em uso capacidades pessoais; c) os conteúdos, como meio e suporte para a constituição das competências; d) a avaliação como parte integrante do processo de formação, que possibilita o diagnóstico de lacunas e a aferição dos resultados alcançados, consideradas as competências a serem constituídas e a identificação das mudanças de percurso eventualmente necessárias. III. a pesquisa, com foco no processo de ensino e de aprendizagem, uma vez que ensinar requer, tanto dispor de conhecimentos e mobilizá-los para a ação, como compreender o processo de construção do conhecimento.

Para Barcellos e Kawamura (2009), o parecer CNE/CP n 9/2001 estabelece que a Licenciatura deve ter um projeto específico em relação ao curso de bacharelado, assumindo, como determina a nova legislação, terminalidade e integralidade. A implicação desse fato é a exigência de currículos próprios da Licenciatura que não se confundam com o bacharelado ou com a antiga formação de professores, tradicionalmente caracterizada como modelo " $3+1$ ".

O modelo de formação utilizada nos cursos de licenciatura entre a década de 1930 e o início da década de 1990 foi o denominado de "modelo $3+1$ ", em que o curso de licenciatura em física era composto de 4 anos, sendo nos três primeiros anos com disciplinas técnicas e específicas da área de física e no último ano com disciplinas ditas pedagógicas.

Barcellos e Kawamura (2009) consideram que o parecer CNE/CP n ${ }^{\circ}$ 9/2001 trata especificamente da articulação entre os conhecimentos a serem ensinados e os conhecimentos pedagógicos que permeiam a prática educativa, visando superar a suposta separação entre o pedagogismo e o conteudismo.

Já o início dos anos 2000 é marcado por propostas centradas no caráter interdisciplinar e integrados dos conteúdos dos cursos de licenciatura que habilitavam para a docência nas disciplinas de matemática, física e química para o ensino de $2^{\circ}$ grau. Segundo essa estrutura curricular os cursos de licenciatura seriam ministrados em 4 anos, sendo os dois primeiros anos dedicados às disciplinas de cunho técnico das áreas e os dois últimos anos de cunho pedagógico. Dessa forma, é possível concluir que os cursos de licenciatura em física passam a partir desse momento a ocorreram sob o aspecto modular e chamado de "modelo $2+2$ ".

\section{Diretrizes Curriculares Nacionais para os cursos de graduação em Física}


A proposta curricular para os cursos de bacharelado e licenciatura em física foi aprovada pela Câmara de Educação Superior (CES) do Conselho Nacional de Educação (CNE) em 04 de dezembro de 2001, por meio do Parecer CNE/CES n 1304/2001 de 07 de dezembro de 2001. Segundo o documento, qualquer que seja a área de atuação do formando, ele deve:

[...] ser um profissional que, apoiado em conhecimentos sólidos e atualizados em Física, deve ser capaz de abordar e tratar problemas novos e tradicionais e deve estar sempre preocupado em buscar novas formas do saber e do fazer científico ou tecnológico. Em todas as suas atividades de investigação deve estar sempre presente, embora associada a diferentes formas e objetivos de trabalho.

Além desse perfil geral, são distinguidos quatro perfis específicos em função da diversificação curricular proporcionada por meio de módulos complementares a um núcleo básico - núcleo este que seria válido a todos esses quatro perfis. Foram caracterizados então o físico-pesquisador, o físico-educador, o físico-tecnólogo e o físico-interdisciplinar. Ainda segundo o Parecer, o físico-educador:

Dedica-se preferencialmente à formação e à disseminação do saber científico em diferentes instâncias sociais, através da atuação no ensino escolar formal, seja através de novas formas de educação científica, como vídeos, "software", ou outros meios de comunicação. Não se ateria ao perfil da atual Licenciatura em Física, que está orientada para o ensino médio formal.

Em relação às competências dos formandos em Física, foram definidas algumas que seriam essenciais a todos os perfis:

1) Dominar princípios gerais e fundamentos da Física, estando familiarizado com suas áreas clássicas e modernas;

2) Descrever e explicar fenômenos naturais, processos e equipamentos tecnológicos em termos de conceitos, teorias e princípios físicos gerais;

3) Diagnosticar, formular e encaminhar a solução de problemas físicos, experimentais ou teóricos, práticos ou abstratos, fazendo uso dos instrumentos laboratoriais ou matemáticos apropriados;

4) Manter atualizada sua cultura científica geral e sua cultura técnica profissional específica;

5) Desenvolver uma ética de atuação profissional e a consequente responsabilidade social, compreendendo a Ciência como conhecimento histórico, desenvolvido em diferentes contextos sóciopolíticos, culturais e econômicos. 
O desenvolvimento dessas competências estaria associado à aquisição de algumas habilidades gerais:

1) Utilizar a matemática como uma linguagem para a expressão dos fenômenos naturais;

2) Resolver problemas experimentais, desde seu reconhecimento e a realização de medições, até à análise de resultados;

3) Propor, elaborar e utilizar modelos físicos, reconhecendo seus domínios de validade;

4) Concentrar esforços e persistir na busca de soluções para problemas de solução elaborada e demorada;

5) Utilizar a linguagem científica na expressão de conceitos físicos, na descrição de procedimentos de trabalhos científicos e na divulgação de seus resultados;

6) Utilizar os diversos recursos da informática, dispondo de noções de linguagem computacional;

7) Conhecer e absorver novas técnicas, métodos ou uso de instrumentos, seja em medições, sejam em análise dos dados (teóricos ou experimentais);

8) Reconhecer as relações do desenvolvimento da Física com outras áreas do saber, tecnologias e instâncias sociais, especialmente contemporâneas;

9) Apresentar resultados científicos em distintas formas de expressão, tais como relatórios, trabalhos para publicação, seminários e palestras.

O Parecer enfatiza que a grade curricular dos cursos de Física deveria possuir um núcleo comum com aproximadamente $50 \%$ da carga horária total. Em seguida, de acordo com os quatro perfis distinguidos, deveriam ser cursados módulos especializados: o bacharelado em física para o perfil físico-pesquisador; a licenciatura em física para o perfil físico-educador; o bacharelado em física aplicada para o perfil físico-tecnólogo; e o bacharelado ou a licenciatura em física associado a outra área de conhecimento (Química, Biologia, Matemática, Tecnologia etc.) para o perfil físico-interdisciplinar.

Embora estabeleça linhas gerais para as grades curriculares dos cursos de Física, o Parecer CNE/CES n ${ }^{\circ}$ 1304/2001 não especificou as disciplinas e/ou os conteúdos que deveriam compor seus projetos pedagógicos. Ainda assim, ao nomear os diferentes perfis sempre iniciando com a palavra "físico", o documento evidencia a importância atribuída à necessidade de que os egressos dominem os fundamentos da física e o ferramental matemático associado. Depreende-se, em consequência, que o núcleo comum preconizado para o início da formação de todos os perfis profissionais deveria ser estruturado com base nesses elementos - de fato, esse modelo ficou conhecido como modelo $2+2$, ou seja, um núcleo comum de dois anos acrescido de um núcleo específico de dois anos (Gatti, 2010). 
Outro indício que suporta essa consideração é a percepção de que as três primeiras competências essenciais definidas para todos os perfis apontam nessa direção.

É possível afirmar que o Parecer considera que um professor de física, por exemplo, seria, em essência, um físico voltado à educação. Nesse sentido, sua formação teria como aspecto fundamental o domínio da física e de seu ferramental matemático, sendo a formação pedagógica geral e específica algo como um adendo. Há que se destacar ainda que, ao relegar as disciplinas associadas à formação pedagógica para a segunda metade do curso, parece haver pouca preocupação por parte do documento em tentar estabelecer inter-relações entre teoria e prática, forma e conteúdo.

As DCN integrantes do Parecer no 1.304/2001, segundo a Resolução CNE/CES no 9, aprovada e publicada no Diário Oficial da União em 26 de março de 2002, deveriam orientar a formulação dos projetos pedagógicos dos cursos de Bacharelado e Licenciatura em Física. Essa Resolução estabeleceu também que tais projetos deveriam explicitar: o perfil dos formandos nas modalidades bacharelado e licenciatura; as competências e habilidades - gerais e específicas a serem desenvolvidas; a estrutura do curso; os conteúdos básicos e complementares e respectivos núcleos; os conteúdos definidos para a Educação Básica, no caso das licenciaturas; o formato dos estágios; as características das atividades complementares; e as formas de avaliação.

Como o foco deste trabalho é pensar aspectos relacionados à formação do professor de Física, acreditamos ser pertinente analisarmos também a Resolução $n^{\circ}$ 2/2015 do Conselho Pleno do CNE, que instituiu as DCN para a formação inicial e continuada de professores em nível superior.

\section{Breve análise da Resolução CNE/CP no 2/2015}

Publicada no Diário Oficial da União em 02 de julho de 2015, a Resolução $\mathrm{CNE} / \mathrm{CP} \mathrm{n}^{\circ}$ 2/2015 instituiu as DCN para a formação inicial e continuada em nível superior de profissionais do magistério para a educação básica, definindo os princípios, fundamentos, dinâmica formativa e procedimentos a serem observados nas políticas, na gestão e nos programas e cursos de formação, bem como no planejamento, nos processos de avaliação e de regulação das instituições de educação que os ofertem.

Entre os princípios da formação de profissionais do magistério da educação básica listados pelo documento, destacamos os seguintes: 
- a formação dos profissionais do magistério (formadores e estudantes) como compromisso com projeto social, político e ético que contribua para a consolidação de uma nação soberana, democrática, justa, inclusiva e que promova a emancipação dos indivíduos e grupos sociais, atenta ao reconhecimento e à valorização da diversidade e, portanto, contrária a toda forma de discriminação;

- a articulação entre a teoria e a prática no processo de formação docente, fundada no domínio dos conhecimentos científicos e didáticos, contemplando a indissociabilidade entre ensino, pesquisa e extensão;

- o reconhecimento das instituições de educação básica como espaços necessários à formação dos profissionais do magistério;

- um projeto formativo nas instituições de educação sob uma sólida base teórica e interdisciplinar que reflita a especificidade da formação docente, assegurando organicidade ao trabalho das diferentes unidades que concorrem para essa formação;

- a compreensão dos profissionais do magistério como agentes formativos de cultura e da necessidade de seu acesso permanente às informações, vivência e atualização culturais.

A Resolução definiu que os cursos de formação inicial de professores para a educação básica em nível superior devem ter, no mínimo, 3.200 horas de efetivo trabalho acadêmico, com duração de, no mínimo, 8 semestres ou 4 anos, sendo 440 horas de prática, 400 horas de estágio supervisionado e pelo menos 2.200 horas dedicadas às atividades formativas estruturadas pelos três núcleos que foram definidos: I) núcleo de estudos de formação geral, das áreas específicas e interdisciplinares, e do campo educacional, seus fundamentos e metodologias, e das diversas realidades educacionais; II) núcleo de aprofundamento e diversificação de estudos das áreas de atuação profissional, incluindo os conteúdos específicos e pedagógicos; e III) núcleo de estudos integradores para enriquecimento curricular.

A integração e a interdisciplinaridade curricular parecem ser valorizadas pelo documento, como no trecho a seguir, que defende a condução do egresso:

[...] à integração e interdisciplinaridade curricular, dando significado e relevância aos conhecimentos e vivência da realidade social e cultural, consoantes às exigências da educação básica e da educação superior para o exercício da cidadania e qualificação para o trabalho.

Assim, as linhas gerais estabelecidas pela Resolução CNE/CP n ${ }^{\circ}$ 2/2015 divergem consideravelmente daquelas definidas pelo Parecer CNE/CES no 1304/2001. Enquanto estas apontam para o professor de física como um "quase bacharel em física" voltado à educação, aquelas apontam para a necessidade de integrar durante a formação do futuro 
professor conhecimentos específicos da área e conhecimentos pedagógicos, forma e conteúdo, teoria e prática.

Há que se reconhecer, portanto, que a Resolução de 2015 apresenta um salto quantitativo e qualitativo no que diz respeito à formação de professores, tanto por ampliar a carga horária mínima exigida, quanto por indicar competências necessárias a serem desenvolvidas ao longo das licenciaturas. Nesse sentido, há que se esperar mobilização para que novas DCN sejam estabelecidas a partir dessa nova resolução e que, no caso específico da física, os antigos modelos $3+1$ e/ou $2+2$ sejam superados por projetos de cursos integradores, envolvendo, dessa forma, princípios gerais e fundamentos da física e conhecimentos relativos aos princípios gerais e fundamentos da educação.

\section{Analisando a grade curricular de um curso de Licenciatura em Física brasileiro}

Optamos por analisar a grade curricular do curso de Licenciatura em Física do Instituto Federal de São Paulo, campus Itapetininga, por se tratar de um curso em que dois dos autores deste texto lecionam e pelo fato de o curso já ter sido reformulado de forma a se adequar à Resolução CNE/CP no 2/2015.

O curso está dividido em oito semestres, perfazendo um total de 3.244,2 horas. Dessas, 400 horas são de estágio curricular supervisionado e 2.644,2 horas são referentes às 47 disciplinas obrigatórias do curso. O Quadro 1, a seguir, explicita sua grade curricular.

Quadro 1: Grade curricular do curso de Licenciatura em Física do IFSP, campus Itapetininga

\begin{tabular}{|l|l|}
\hline \multirow{4}{*}{ SEMESTRE } & \multicolumn{1}{c|}{ COMPONENTE CURRICULAR } \\
\hline \multirow{5}{*}{-} & Fundamentos de Matemática Elementar \\
\cline { 2 - 2 } & Vetores e Geometria Analítica \\
\cline { 2 - 2 } & Leitura e Interpretação de Textos Científicos \\
\cline { 2 - 2 } & Fundamentos da Mecânica Clássica nas Ciências Naturais e Matemática \\
\hline \multirow{2}{*}{$\sim$} & História da Educação \\
\cline { 2 - 2 } & Introdução à Ciência Experimental \\
\hline & Cálculo Diferencial e Integral I \\
\cline { 2 - 2 } & Gravitação e Leis de Conservação \\
\cline { 2 - 2 } & Astronomia \\
\cline { 2 - 2 } & Filosofia da Educação \\
\hline
\end{tabular}




\begin{tabular}{|c|c|}
\hline & História da Ciência e Tecnologia \\
\hline & Química Geral \\
\hline & Cálculo Diferencial e Integral II \\
\hline & Mecânica dos Sólidos \\
\hline m & Práticas Pedagógicas para a Educação a Distância \\
\hline & Fundamentos dos Fenômenos Ondulatórios nas Ciências Naturais e Matemática \\
\hline & Língua Brasileira de Sinais \\
\hline & Educação, Cultura e Sociedade \\
\hline & Didática Geral \\
\hline & Cálculo Diferencial e Integral III \\
\hline & Fundamentos da óptica nas Ciências Naturais e Matemática \\
\hline$\nabla$ & Equações Diferenciais \\
\hline & Psicologia da Educação \\
\hline & Língua Brasileira de Sinais aplicada ao Ensino da Física \\
\hline & Fundamentos da Termodinâmica nas Ciências Naturais e Matemática \\
\hline & Cálculo Diferencial e Integral IV \\
\hline in & Fundamentos da Eletricidade nas Ciências Naturais e Matemática \\
\hline & Sociologia da Educação \\
\hline & Oficina de projetos de Ensino de Física I \\
\hline & Mecânica dos Fluidos \\
\hline & Oficina de projetos de Ensino de Física II \\
\hline & Informática e Objetos de Aprendizagem \\
\hline 6 & Políticas Públicas e Organização da Educação Brasileira \\
\hline & Fundamentos do Eletromagnetismo \\
\hline & Psicologia da adolescência \\
\hline & Física Moderna e Contemporânea \\
\hline & Mecânica Racional \\
\hline & Física Quântica \\
\hline$r$ & Práticas Pedagógicas Inclusivas \\
\hline & Educação em Direitos Humanos \\
\hline & Relatividade \\
\hline & Oficina de projetos de Ensino de Física III \\
\hline & Física Aplicada aos Fenômenos Biológicos \\
\hline$\infty$ & Oficina de projetos de Ensino de Física IV \\
\hline & Práticas Pedagógicas para a Educação de Jovens e Adultos \\
\hline & Física do Estado Sólido \\
\hline & Tópicos de Divulgação Científica \\
\hline
\end{tabular}

Fonte: Elaboração própria

RIAEE - Revista Ibero-Americana de Estudos em Educação, Araraquara, v. 13, n. 2, p. 871-884, abr./jun., 2018. E-ISSN: 1982-5587. 
Do total de 47 disciplinas do curso, podemos dizer que dezenove (cerca de $40 \%$ ) são disciplinas de caráter pedagógico geral (área da educação) ou específico (área de ensino de física/ciências). Trata-se das seguintes disciplinas: História da Educação; Filosofia da Educação; Práticas Pedagógicas para a Educação a Distância; Língua Brasileira de Sinais; Educação, Cultura e Sociedade; Didática Geral; Psicologia da Educação; Língua Brasileira de Sinais aplicada ao Ensino da Física; Sociologia da Educação; Oficina de projetos de Ensino de Física I; Oficina de projetos de Ensino de Física II; Políticas Públicas e Organização da Educação Brasileira; Psicologia da adolescência; Práticas Pedagógicas Inclusivas; Educação em Direitos Humanos; Oficina de projetos de Ensino de Física III; Oficina de projetos de Ensino de Física IV; Práticas Pedagógicas para a Educação de Jovens e Adultos; Tópicos de Divulgação Científica.

Há que se esclarecer que para definirmos se umadisciplina é ou não de caráter pedagógico, levamos em conta, sobretudo, a presença ou não de palavras/expressões como “educação", “ensino”, “práticas pedagógicas”, “didática”, “aprendizagem” e "escolar” em seus títulos. Outro critério foi a reflexão a respeito do sentido da disciplina para um curso de graduação em física: se a disciplina faz sentido especialmente para a formação de professores de física, a princípio, trata-se de uma disciplina de caráter pedagógico; se a disciplina faz sentido também para a formação de bacharéis em física, a princípio, trata-se de uma disciplina específica da área de conhecimento - física, no caso.

Em termos da distribuição das disciplinas pedagógicas ao longo dos oito semestres de curso, o gráfico da Figura 1, a seguir, sistematiza de que forma ela é feita.

Figura 1: Distribuição das disciplinas pedagógicas ao longo do curso

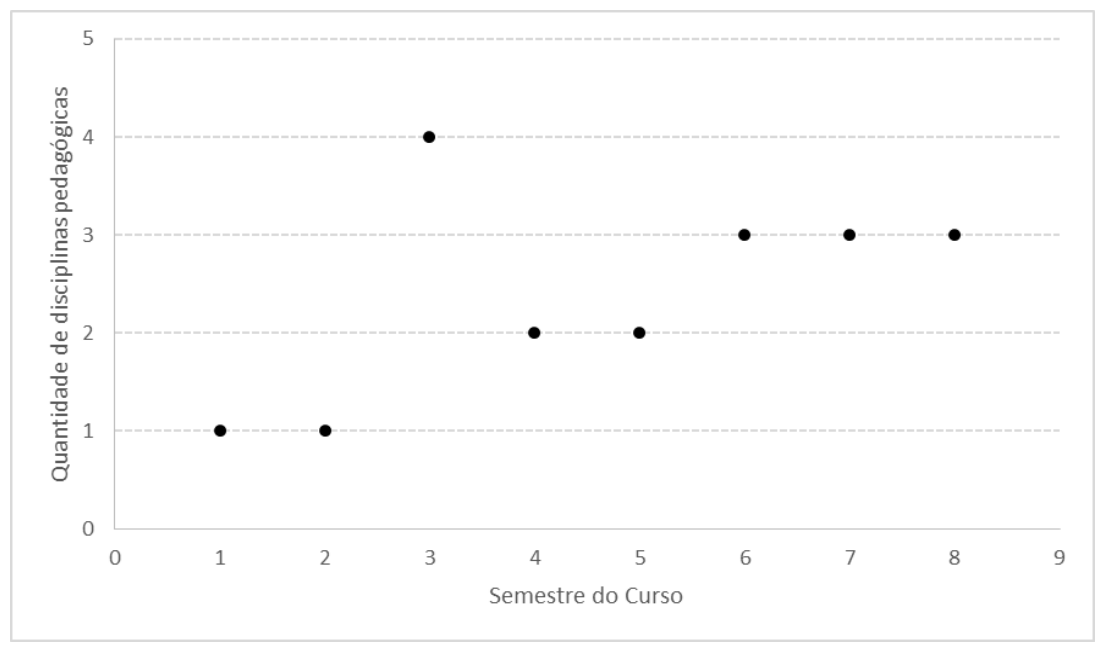

Fonte: Autores 
Embora no primeiro ano de curso haja apenas duas disciplinas de caráter pedagógico, é possível notar que em todos os semestres do curso elas se fazem presentes. Além disso, se dividíssemos o curso em duas metades, veríamos que, na primeira delas, o futuro professor cursaria oito disciplinas relacionadas à docência. Já na segunda, seriam cursadas onze disciplinas desse tipo. Essa distribuição relativamente homogênea das disciplinas de caráter pedagógico ao longo do curso evidencia, em nossa opinião, que os ideais definidos pelo Parecer CNE/CES n 1304/2001 - o chamado "modelo 2 + 2" - não repercutiram em sua grade curricular. Podemos afirmar o oposto em relação à influência da Resolução CNE/CP no 2/2015, pois além de estabelecer cargas horárias mínimas para o curso e para o estágio curricular supervisionado, essa Resolução preza pela integração entre conhecimentos específicos da área e conhecimentos pedagógicos.

Por fim, vale observar que no curso de Licenciatura em Física do IFSP, campus Itapetininga, as 400 horas obrigatórias de estágio curricular supervisionado - que também poderia ser caracterizado como um elemento de caráter pedagógico - podem ser realizadas a partir da segunda metade do curso, não estando atreladas a nenhuma disciplina específica.

\section{Considerações finais}

O presente trabalho realizou uma análise do curso de Licenciatura em Física do Instituto Federal de Educação, Ciência e Tecnologia de São Paulo (IFSP), campus Itapetininga.

Neste texto apresentamos um breve resumo das transformações ocorridas no modelo de formação nos cursos de licenciatura em física, que passou inicialmente de um "modelo 3+1" para um modelo denominado "modelo 2+2". Transformações estas ocorridas nas propostas dos cursos de licenciatura em física para atenderem as legislações vigentes.

O modelo denominado 3+1 de formação de professores nos cursos de licenciatura predominou na educação brasileira desde o início da década de 1930 até meados da década de 2015, quando começou a ser substituído legalmente pelo modelo denominado $2+2$.

O chamado "modelo $2+2$ " trouxe implicações significativas na grade curricular e nos projetos pedagógicos dos cursos de licenciatura em física, principalmente pela influência da Resolução CNE/CP no 2/2015. Pois além de estabelecer cargas horárias 
mínimas para o curso e para o estágio curricular supervisionado, essa Resolução preza pela integração entre conhecimentos específicos da área e conhecimentos pedagógicos.

Apesar do professor a ser formado no "modelo 2+2" ser mais adequado em termos teóricos ainda há muitos pontos a serem aperfeiçoados nesse modelo. Que disciplinas devem ser ofertadas? Qual a carga horária dessas disciplinas? Quais disciplinas devem ser obrigatórias? Como devem ser trabalhadas tais disciplinas? Ainda são muitas questões em aberto e que precisam ser respondidas para que possamos aprimorar a formação dos professores de física formados nos cursos de licenciatura em física no Brasil.

\section{REFERÊNCIAS}

BARCELLOS, Marcília.; KAWAMURA, Maria Regina Dubeux. Licenciatura em física: as novas tendências e a pesquisa em ensino. In: VII ENPEC. UFSC, Florianópolis, 2009.

BRASIL. Conselho Nacional de Educação. Parecer CNE/CP n ${ }^{\circ}$ 009, aprovado em 8 de maio de 2001, Diretrizes Curriculares Nacionais para a Formação de Professores da Educação Básica, em nível superior, curso de licenciatura, de graduação plena Homologado em 17/01/2002, publicado no Diario Oficial da União - DOU, em $18 / 01 / 2002$.

BRASIL. Ministério da Educação e Cultura. Diretrizes Curriculares para os Cursos de Graduação. Disponível em: 〈http://www.mec.gov.br/Sesu/diretriz.shtm〉. Acesso em: 10 jan. 2018.

BRASIL. MEC. Parecer $\mathbf{n}^{\mathbf{0}}$ CNE/CES no 1304/2001, de 03 de abril de 2001 - Diretrizes Curriculares para os Cursos de Bacharelado e Licenciatura em Física.

BRASIL. MEC. Parecer CNE/CP no 9/2002.Diretrizes Curriculares Nacionais para a Formação de Professores da Educação Básica, em nível superior, curso de licenciatura, de graduação plena. Brasília.

BRASIL. MEC. Resolução CNE/CP n⿳ 2/2015: Diretrizes Curriculares Nacionais para a Formação inicial em nível superior (cursos de licenciatura, cursos de formação pedagógica ara graduados e cursos de segunda licenciatura) e para a formação continuada. Brasília.

GATTI, Bernardete A. Formação de professores no Brasil: características e problemas. Educação \& Sociedade, v. 31, n. 113, p. 1355-1379, 2010.

SILVA, André Coelho da.; SHIGUNOV NETO, Alexandre.; FORTUNATO, Ivan. (2017). Uma análise comparativa da formação de professores de física no Brasil e em Portugal. In: SHIGUNOV NETO, Alexandre.; FORTUNATO, Ivan. Docência e Pesquisa nos cursos de Licenciatura em Física. São Paulo: Edições Hipótese. 


\section{Como citar este artigo:}

NETO, Alexandre Shigunov.; SILVA, André Coelho da. Formação do professor de Física: análise do curso de Licenciatura em Física do IFSP. Revista Ibero-Americana de Estudos em Educação, Araraquara, v. 13, n. 2, p. 871-884, abr./jun., 2018. E-ISSN: 19825587. DOI: 10.21723/riaee.v13.n2.2018.11268

Submissão em: 20/12/2017

Aprovação final em: 20/03/2018 